\title{
Produção científica sobre psicologia dos desastres: Uma revisão da literatura nacional
}

Ana Paula de Araujo Braga. Associação de Pais e Amigos dos Excepcionais de Vitória.

Priscilla de Oliveira Martins-Silva. Universidade Federal do Espirito Santo.

Luziane Zacché Avellar. Universidade Federal do Espírito Santo.

Kelly Guimarães Tristão. Centro Universitário Faesa.

Pedro Machado Ribeiro Neto. Centro Universitário do Espírito Santo.

\section{Resumo}

As notícias sobre a ocorrência de desastres têm-se tornado parte do cotidiano das brasileiras e brasileiros nos últimos anos, dada a elevada quantidade de eventos climáticos extremos agravados pela degradação ambiental e problemas sociais severos. Este estudo apresenta uma revisão sistemática da literatura científica produzida no Brasil sobre a Psicologia dos Desastres, a fim de se conhecer como o evento e os fenômenos sociais inerentes a ele estão sendo tomados como objeto de estudo pela Psicologia, dando enfoque aos desastres socioambientais. A revisão recuperou 11 artigos nas bases de dados Bireme e SciELO, considerando como critérios de inclusão: artigos produzidos no Brasil, temporalidade entre 2005 a 2015 e que discutissem apenas desastres socioambientais. Os resultados mostram que o desastre ainda é um desafio para o estudo da psicologia, existindo poucos estudos que são em sua maioria teóricos. Observa-se que existe um campo profícuo para a construção do conhecimento na temática. Palavras chave: psicologia; risco; vulnerabilidade; desastre.

\begin{abstract}
Scientific literature on disasters in psychology: A review of national literature. The news about the occurrence of disasters has become part of the daily life of Brazilians in recent years, given the high amount of extreme climatic events aggravated by environmental degradation and severe social problems. This study presents a systematic review of the scientific literature produced in Brazil on Disaster Psychology, in order to know how the event and all the social phenomena inherent to it are being taken as an object of study by Psychology, focusing on socio-environmental disasters. The review retrieved 11 articles in the databases Bireme and SciELO, considering as inclusion criteria: articles produced in Brazil, temporality between 2005 and 2015 and that only discussed socioenvironmental disasters. The results show that the disaster is still a challenge for the study of psychology, with few studies that are mostly theoretical. It is observed that there is a profitable field for the construction of knowledge in the theme.
\end{abstract}

Keywords: psychology; risk; vulnerability; disaster.

\section{Resumen}

La literatura científica sobre desastres en psicología: Una revisión de la literatura nacional. Las noticias sobre la ocurrencia de desastres se han convertido en parte del cotidiano de brasileñas y brasileños en los últimos años, dada la elevada cantidad de eventos climáticos extremos agravados por la degradación ambiental y problemas sociales severos. Este estudio presenta una revisión sistemática de la literatura científica producida en Brasil sobre la psicología de desastres, con el fin de saber cómo están tomando el caso de desastres y todos los fenómenos sociales inherentes a ella como estudiado por la psicología, centrándose en los desastres sociales y medioambientales. La revisión se recuperó 11 artículos en las bases de datos de BIREME y SciELO, teniendo en cuenta los siguientes criterios de inclusión: los artículos producidos en Brasil, la temporalidad entre 2005-2015 y discutir sólo los desastres ambientales. Los resultados muestran que el desastre sigue siendo un reto para el estudio de la psicología, hay pocos estudios que son en su mayor parte teórica. Se observa que existe un campo fértil para la construcción del conocimiento en la materia.

Palabras clave: psicología; riesgo; vulnerabilidade; desastre. 
Cotidianamente somos absorvidos por inúmeras notícias sobre a ocorrência dos mais diversos tipos de emergências e desastres. Os desastres causam o desespero a quem é diretamente afetado por eles e comoção em quem não experiencia uma situação como essa in loco, mas que ainda assim é afetado, pois, é atravessado por seus impactos através das mídias que noticiam tais acontecimentos a todo o momento.

No Brasil, os dados oficiais mais atualizados sobre a ocorrência de desastres naturais são de 2013, e estão reunidos na terceira edição do Anuário Brasileiro de Desastres Naturais, que é uma publicação produzida pelo Ministério da Integração Nacional [MIN]. Ao longo dessas três edições do Anuário, são retratados os principais desastres naturais ocorridos até 2013 no Brasil, o que permite que a comunidade em geral, bem como a comunidade técnico-científica, conheça o perfil destes eventos em nosso país (MIN, 2014).

Outra produção importante é o Atlas Brasileiro de Desastres Naturais, organizado pela Universidade Federal de Santa Catarina [UFSC], dentro do Centro Universitário de Estudos e Pesquisas sobre Desastres [CEPED]. Nesse estudo foram mapeados os desastres ocorridos no Brasil entre 1991 e 2012, tendo sido feito também o levantamento dos desastres ocorridos em cada estado e o Distrito Federal (UFSC \& CEPED, 2013).

Segundo o Atlas Brasileiro de Desastres Naturais, houve no Brasil um aumento no número de registros de desastres na década de 2000 e nos anos de 2010, 2011 e 2012. Neste período observa-se um total de 38.996 registros, sendo que 8.515 (22\%) são da década de 1990; 21.741 (56\%) da década de 2000; e 8.740 (22\%) apenas dos anos de 2010, 2011 e 2012. Ocorre que, não se pode afirmar que esses números representem o real aumento da ocorrência de desastres naturais devido a fragilidade e dificuldade que a Defesa Civil tem de manter atualizados seus registros. Contudo, os dados apontam um potencial aumento no número de desastres naturais, bem como os esforços e a melhoria para o registro e organização da Defesa Civil (UFSC \& CEPED, 2013).

Em 2013, os desastres naturais afetaram um total de 18.557.233 pessoas, sendo que 168.269 pessoas ficaram enfermas ou feridas e 183 foram vítimas fatais, e destes, 41 óbitos ocorreram em virtude de deslizamentos e 38 por enxurradas. As chuvas abaixo dos padrões normais climatológicos na região Semiárida do Brasil geraram a continuidade e o agravamento do desastre da seca, afetando um total de 11.550 .159 e deixando 68.047 pessoas enfermas (MIN, 2014).
A classificação e conceituação dos desastres é algo de extrema importância para a determinação de planos de ações e enfrentamento. A classificação imprime inclusive legalidade ao termo, o que possibilita incluir os dados nacionais em bancos de dados internacionais, como os da ONU, e viabiliza a estados e municípios a declaração de estados de emergência ou calamidade, a fim de que sejam tomadas as medidas necessárias para assistência e aplicação de planos de contingência (MIN, 2012).

Outro motivo igualmente importante para se ter uma classificação dos desastres é a necessidade de registro desses fenômenos no contexto histórico do país. A codificação permite a formação de um banco de dados, que poderá ser utilizado para uma análise contextualizada da ocorrência de desastres no território nacional, possibilitando o planejamento de medidas preventivas e preparatórias para o enfrentamento desses eventos adversos (MIN, 2012).

Além do que foi mencionado, a classificação, considerando meramente o desastre ou tomando-o como único objeto de estudo, é eficaz para o corpus de um saber técnico científico, que busca de forma pragmática, evitar quando possível, ou minimizar os impactos dos desastres.

Esse desastre, entretanto, incide sobre um tecido social muito vulnerável e mostra-se cada vez mais necessário um novo debate sobre a construção do saber sobre esse evento. Valencio (2009) afirma que, no conceito de desastre, subjaz necessariamente uma dimensão social, e seria de esperar que a Defesa Civil necessariamente dialogasse com os cientistas sociais para melhor entender a natureza da afetação, seja no aspecto dos danos humanos, materiais e imateriais, dos prejuízos econômicos e da destruição de toda a ordem, o que é explicado em grande medida, no caso brasileiro, numa perspectiva histórico-estrutural. Procurar compreender os desastres no âmbito do tecido social significa ampliar a visão da noção de risco.

Nesse sentido, é relevante pensar sobre a noção de risco, que é tomada a partir de um saber técnico, que é o que normalmente baliza as avaliações e ações que devem ser tomadas no caso de desastres. Evangelista (2009) levanta a questão sobre como a construção do saber sobre o risco e suas formas de prevenção e evitação dão-se de maneira factual e apenas baseada numa racionalidade científica. Esse conhecimento é disseminado em treinamentos, como ele mesmo afirma, por meio de discursos que procura orientar/determinar 
um conjunto de atitudes a serem tomadas em contextos de risco e das respostas aos desastres levados a efeito. Contudo, os principais atores desse processo, os afetados, nem sempre têm a compreensão dos pressupostos que implicam acatar tais disposições (Evangelista, 2009).

O fato de os afetados por muitas vezes permanecerem morando nas áreas inadequadas para habitação, imediatamente os colocam em situação de vulnerabilidade e concomitantemente num grupo de risco. Vargas (2009) sustenta que "[...] no universo do debate sobre o risco, o discurso técnico se confronta com as práticas cotidianas resultantes de uma luta que é material e simbólica e que se dá no plano imediato da vida dos sujeitos" (p. 82). Desse modo, observa-se que, para além das questões técnicas e práticas envolvendo a dinâmica do risco, há questões pessoais, de vivências, lutas e vínculos que exigem um outro modo de enxergá-lo.

Em recente estudo, Tavanti e Spink (2014) problematizam essa questão na discussão de seus resultados, assegurando que numa área de risco socioambiental de São Paulo há a existência da convivência com as situações de riscos e de desastres na região. Os autores identificaram ainda que as decisões relacionadas ao que fazer e como fazer diante das ocorrências são tomadas pelos afetados isoladamente, ou em conjunto com os familiares, amigos e vizinhos. Essa forma de tomar decisões evidencia uma inoperância e/ou ausência das ações de prevenção por parte das instituições e serviços públicos locais, em particular, daqueles vinculados à Defesa Civil na região (Tavanti \& Spink, 2014).

Essa informação corrobora a exposição anterior de que há a necessidade de o saber técnico contemplar o saber popular da vivência e experiência dos afetados pelos desastres. Para colaborar com essa interlocução, as ciências humanas, especialmente a psicologia, pode ser um potente aliado, buscando preencher esta lacuna e contribuindo para a construção de comunidades mais seguras.

Diniz Neto e Belo (2015) salientam que a Psicologia como um campo de saber específico contribuiu inicialmente com um instrumental derivado da teoria e prática clínica, porém, na medida em que avançaram os estudos, foi verificado que este modelo clínico se mostrou insuficiente para compreender a complexa dinâmica das emergências, bem como produzir intervenções produtivas. Diante dessa realidade verifica-se atualmente que a Psicologia das Emergências e Desastres tem direcionado seu foco para o estudo e intervenções a partir das questões da Saúde Coletiva (Diniz Neto \& Belo, 2015).
Com o propósito de mapear o que tem sido produzido na literatura especializada acerca da Psicologia das Emergências e Desastres, esse estudo tem como objetivo realizar uma revisão sistemática da literatura científica produzida no Brasil sobre esta temática. Especificamente, objetiva-se, conhecer como o evento desastre e todos os fenômenos sociais inerentes a ele estão sendo tomados como objeto de estudo pela Psicologia, dando enfoque aos Desastres Socioambientais, mais comumente denominados como Desastres Naturais, ou seja, desastres que tem como agente desencadeador de suas ocorrências, eventos da natureza. Assim, podemos colaborar para a construção de um saber e ampliar uma área de estudo, que no Brasil ainda é incipiente.

\section{Metodologia}

Foi realizada uma revisão sistemática de literatura nas bases de dados virtuais Biblioteca Virtual em Saúde (Bireme) e Scientific Eletronic Library Online (SCIELO) ${ }^{1}$. Como descritores para as buscas, foram usadas as palavras "psychology AND disasters" e "psychology AND natural disasters" e seus respectivos correspondentes em português.

O primeiro critério de inclusão foi a indexação em bases de dados nacionais. Nesta fase foram recuperados 61 documentos. Em seguida, foi aplicado o critério de inclusão de temporalidade, refinando a busca para produções publicadas entre os anos de 2005 a 2015. Nesse momento, foram capturadas 54 publicações. Depois foi aplicado o critério de exclusão, em que foram descartados artigos que não tivessem estudos ou discussões relativas aos desastres ocorridos no Brasil. Assim, excluíram-se todas as publicações de outros países, reduzindo a amostra para 26 publicações.

Nesse momento, efetuou-se uma leitura exploratória dos resumos, buscando a certificação de que cumpririam os critérios de inclusão e exclusão ora mencionados. Constatou-se então, que dois artigos não se referiam a desastres naturais e outros dois documentos tratavam-se de teses de doutorado, diminuindo assim a amostra para 22. Desses 22 artigos capturados, 11 estavam repetidos, totalizando uma amostra de 11 artigos retidos nesta revisão.

Para a realização da análise dos dados foram empregadas a estatística descritiva (Silvestre, 2007) e Análise de Conteúdo (Bardin, 1977/2011). As categorias desenvolvidas para a pesquisa foram: (1) natureza do artigo: 
teórico ou teórico-empírico; (2) abordagem metodológica utilizada: quantitativa ou qualitativa; (3) quantitativo de artigos por ano; (4) formação acadêmica dos autores; (5) localização geográfica da vinculação institucional dos autores; (6) prevenção/noção de risco/vulnerabilidade; (7) caracterização e conceituação de desastres; (8) manejo da situação traumática; (9) consequências dos desastres e (10) atuação/contribuição da psicologia.

\section{Resultados e Discussões}

Foram identificados 11 artigos de acordo com os critérios de inclusão e exclusão estabelecidos. A partir dessa amostra foi possível identificar alguns aspectos sob os quais o desastre natural é estudado no Brasil, apesar de um número restrito de artigos encontrados sobre a temática. Essa situação parece estar de acordo com o momento em que se encontra a produção do conhecimento sobre o tema. É um tema em fase embrionária em termos da produção do conhecimento em Psicologia. Entretanto, um indicativo de crescimento, ainda que modesto no interesse em pesquisar esta temática, nos é apresentado por Diniz Neto e Belo (2015) que em levantamento bibliográfico identificaram que, embora a produção sobre o tema seja incipiente na língua portuguesa, há um interesse na academia, pois 15 dos 22 trabalhos elencados pelos autores são teses, dissertações ou monografias de especialização.

A seguir serão apresentados os resultados e a análise do material encontrado por meio de um mapeamento dos estudos selecionados, no intuito de localizar os dados mais gerais de cada um dos artigos, assim como, uma exposição das temáticas mais relevantes levantadas.

Primeiramente será apresentado a análise referente às características gerais dos artigos. Essa primeira parte usou como ferramenta de análise a estatística descritiva (Silvestre, 2007). Posteriormente, apresenta-se a análise referente às temáticas abordadas nos artigos, para isso foi realizado a Análise de Conteúdo (Bardin, 1977/2011).

\section{Características dos Artigos}

Dentro do modelo proposto, foram identificados 11 artigos, sendo três classificados como teórico-empíricos e oito como teóricos. Os artigos teórico-empíricos usaram, todos, abordagem qualitativa de pesquisa. Entre os oito artigos teóricos, três foram categorizados como ensaios teóricos e cinco como revisões de literatura como ilustra a Tabela 1.

Tabela 1. Identificação dos Estudos Selecionados.

\begin{tabular}{|c|c|c|c|c|c|}
\hline $\mathbf{N}$ & Título & Referência & Local & Natureza do artigo & $\begin{array}{c}\text { Formação acadêmica } \\
\text { dos autores }\end{array}$ \\
\hline 1 & $\begin{array}{l}\text { Psicologia nas emergências: uma nova prática } \\
\text { a ser discutida. }\end{array}$ & Paranhos \& Werlang (2015) & RS & $\begin{array}{c}\text { Teórico/ Revisão de } \\
\text { Literatura }\end{array}$ & Psicologia \\
\hline 2 & $\begin{array}{l}\text { O desastre na perspectiva sociológica e psi- } \\
\text { cológica. }\end{array}$ & Favero, Sarriera, \& Trindade (2014) & RS & $\begin{array}{c}\text { Teórico/ Revisão de } \\
\text { Literatura }\end{array}$ & Psicologia \\
\hline 3 & $\begin{array}{l}\text { Ações locais e prevenção: um estudo com } \\
\text { adolescentes que vivem em áreas de risco } \\
\text { socioambiental. }\end{array}$ & Tavanti \& Spink (2014) & SP & Teórico-Empírico & Psicologia \\
\hline 4 & $\begin{array}{c}\text { A atuação do psicólogo diante dos desastres } \\
\text { naturais: uma revisão. }\end{array}$ & Alves, Lacerda, \& Legal (2012) & $\mathrm{SC}$ & $\begin{array}{c}\text { Teórico/ Revisão de } \\
\text { Literatura }\end{array}$ & Psicologia \\
\hline 5 & $\begin{array}{l}\text { Desastres naturais: perdas e reações psicológi- } \\
\text { cas de vítimas de enchente em Teresina-PI. }\end{array}$ & Gomes \& Cavalcante (2012) & $\mathrm{PI}$ & Teórico-Empírico & Psicologia \\
\hline 6 & $\begin{array}{c}\text { Participação dos núcleos de defesa civil do } \\
\text { município de Vitória na gestão de desastres } \\
\text { naturais. }\end{array}$ & Lugon \& Palassi (2012) & ES & Teórico-Empírico & $\begin{array}{l}\text { Administração/ } \\
\text { Psicologia }\end{array}$ \\
\hline 7 & $\begin{array}{l}\text { As contribuições da psicologia nas emergên- } \\
\text { cias e desastres. }\end{array}$ & Melo \& Santos (2011) & SP & $\begin{array}{c}\text { Teórico/ Revisão de } \\
\text { Literatura }\end{array}$ & $\begin{array}{l}\text { Psicologia/ } \\
\text { Geografia }\end{array}$ \\
\hline 8 & $\begin{array}{c}\text { A construção de uma agenda para as questões } \\
\text { de gênero, desastres socioambientais e desen- } \\
\text { volvimento. }\end{array}$ & Freitas (2010) & SC & $\begin{array}{l}\text { Teórico/ Ensaio } \\
\text { Teórico }\end{array}$ & Serviço Social \\
\hline 9 & $\begin{array}{c}\text { A seca enquanto um hazard e um desastre: } \\
\text { uma revisão teórica }\end{array}$ & Favero \& Diesel (2008) & RS & $\begin{array}{c}\text { Teórico/ Revisão de } \\
\text { Literatura }\end{array}$ & $\begin{array}{c}\text { Psicologia/ } \\
\text { Engenharia Florestal }\end{array}$ \\
\hline 10 & $\begin{array}{l}\text { Enfrentamento de desastres naturais: o uso } \\
\text { de um coping coletivo. }\end{array}$ & Krum, Menna Barreto, \& Bandeira (2008) & RS & $\begin{array}{l}\text { Teórico/ Ensaio } \\
\text { Teórico }\end{array}$ & Psicologia \\
\hline 11 & $\begin{array}{c}\text { A abordagem psicológica da problemática dos } \\
\text { desastres: um desafio cognitivo e profissional } \\
\text { para a psicologia. }\end{array}$ & Mattedi (2008) & SC & $\begin{array}{c}\text { Teórico/ Ensaio } \\
\text { Teórico }\end{array}$ & Ciências Sociais \\
\hline
\end{tabular}


Considerando a formação acadêmica das autoras e autores, seis artigos têm a autoria de psicólogas e psicólogos unicamente. Em três deles, além de profissionais da psicologia, há a coautoria com profissionais das áreas de Geografia, Administração e Engenharia Florestal. Também se verificou que dois artigos foram escritos por autoras e autores das Ciências Sociais e Serviço Social.

Houve uma predominância de publicações oriundas da região Sul do país, com sete artigos, sendo cinco do estado do Rio Grande do Sul e dois de Santa Catarina. Em seguida, o maior número de produções encontra-se na região Sudeste com três artigos, sendo dois realizados no estado de São Paulo e um no Espírito Santo. A região Nordeste contribuiu com uma produção do estado do Piauí. Não foram encontradas publicações nas regiões Centro-oeste e Norte.

Quanto às datas de publicação, houve maior predominância de publicações nos anos 2008 e 2012 com três artigos publicados em cada ano. Em 2014, foram publicados dois artigos e em 2010, 2011 e 2015 houve uma publicação em cada ano. Nota-se um vácuo na produção nos anos de 2005 a 2007 e em 2009 e 2013. Verifica-se que os anos de 2012, 2014 e 2015 contemplam seis dos 11 artigos incluídos na pesquisa.

\section{Temáticas dos Artigos}

Neste bloco, serão apresentados os principais assuntos abordados na problemática dos desastres naturais encontrados nos estudos selecionados. Trata-se de pontos de discussão e reflexão que se mostram preponderantes para o entendimento de como se compreende o desastre na literatura científica brasileira em Psicologia.

Risco/Vulnerabilidade/Prevenção. Risco, vulnerabilidade e prevenção mostram-se como conceitos-chave no estudo e pesquisa sobre desastres naturais, pois, em toda sua dinâmica eles estão subjacentes. Eles foram discutidos nos artigos 1, 2, 3, 4, 5, 6, 8, 9 e 11 .

Os estudos elencados na pesquisa mostram uma relação intrínseca entre a noção de risco, vulnerabilidade e prevenção, sendo que, a vulnerabilidade e o risco são fatores que convergem e a prevenção caracteriza-se como uma forma para a redução de ambos, sendo assim impossível discuti-los em categorias distintas.

Favero, Sarriera e Trindade (2014), no artigo 2, apontam a importância do conceito de risco numa dimensão em que os desastres não ocorrem desvinculados do contexto social. Coadunando com esse pensamento, Mattedi (2008), no artigo 11, afirma que as populações mais carentes se mostram como as mais vulneráveis aos impactos dos desastres naturais por existir um processo de institucionalização dos riscos, onde os danos causados pelos desastres são confrontados por ações parciais que favorecem a ocupação de áreas de risco, caracterizando o processo cíclico de desastres-danos/reparação-desastre.

O risco, na perspectiva dos artigos elencados nessa categoria, pode ser compreendido como parte de um processo mal estabelecido de desenvolvimento das comunidades, assim como pode ser configurado dentro da perspectiva de eventos extremos futuros. Ambas as formas de o perceber estão ligadas à situação de vulnerabilidade, que na medida em que provoca o risco na primeira perspectiva, deixa as comunidades mais suscetíveis às consequências severas dos eventos na perspectiva seguinte.

Favero et al. (2014), no artigo 2, complementam ressaltando a importância de considerar que a perspectiva a partir da qual se analisa um evento modifica também a compreensão do risco de desastre a que uma determinada população está exposta, de modo a naturalizá-lo como algo externo, ou compreendê-lo como parte de um contexto de vulnerabilidade social.

Outra perspectiva de compreensão dos riscos o determina como o evento em si, ou seja, os eventos deflagradores do desastre como, por exemplo, as enchentes, chuvas, deslizamentos de massas. Esse atributo denota uma forma técnica de perceber o risco, o que, segundo Freitas (2010), no artigo 8, não abarca sua totalidade de pressupostos, uma vez que as condições econômicas, sociais e culturais influenciam no efeito dos desastres expondo a população a danos secundários, como em relação à emprego.

Pelo modo como o risco e vulnerabilidade se entrelaçam, a prevenção surge como dispositivo para minimizar esses fatores agravantes para as consequências dos desastres. Uma forma de realizar a prevenção mencionada nos estudos é a educação.

Lugon e Palassi (2012), no artigo 6, concordam que não é possível conter fenômenos naturais, como chuvas por exemplo, mas é possível promover uma educação ambiental na sociedade no sentido de dispensar o lixo de forma adequada, não ocupar áreas inadequadas para moradia como encostas e beira dos rios. Segundo esses autores, é possível por meio da educação realizar campanhas para uma mudança na cultura das comunidades, bem como medidas de fiscalização e aplicação da legislação vigente. 
Favero et al. (2014), no artigo 2, concordam que a educação permite a comunidade acesso à informação, fazendo com que as pessoas conheçam o risco ao qual estão expostas, e possam reduzi-lo. Caso isso não aconteça, segundo os autores, a comunidade tem aumentada a sua vulnerabilidade.

Alves, Lacerda e Legal (2012), no artigo 4, também concordam com essa afirmativa e ainda acrescentam que a psicóloga e o psicólogo são importantes agentes para compor a criação e execução dessas medidas junto às comunidades e órgãos de controle e gestão dos desastres, como poder público e Defesa Civil.

Caracterização e Conceituação de Desastres. Foi dispensada grande atenção por parte dos autores na conceituação e caracterização dos desastres, uma vez que, em quase todos os artigos, foram buscadas referências para se denominar esse evento. Verifica-se que essas definições caracterizam os desastres de três formas: consequências dos desastres, antecedentes dos desastres ou tipos de desastres.

Nos Artigos 1, 2, 4, 5 e 7 fica expressa a dimensão dos desastres no que ele acarreta como consequências por sua magnitude para indivíduos e sociedade. Paranhos e Werlang (2015), no artigo 1 por exemplo, caracterizam desastres como situações desencadeadoras de estresse por sua imprevisibilidade e perigo à integridade física e mental. Favero et al. (2014), no artigo 2, também consideram desastres como um período de crise caracterizados pelo alto grau de estresse coletivo.

Os autores dos artigos 4 e 5, ainda atribuem como característica dos desastres a ruptura da ordem, provocando distúrbios em serviços essenciais, como a saúde. Danos humanos, ambientais e materiais também são enumerados pelos autores em consonância com a Política Nacional de Defesa Civil (MIN, 2007).

Outra característica atribuída aos desastres diz respeito às questões sociais e políticas inerentes a ele, que incidem diretamente sobre a vulnerabilidade socioambiental na qual grande parcela da população se encontra. Nesse sentido, fica evidenciada a dimensão dos antecedentes que potencializam o grau de destruição dos eventos da natureza. No artigo 7, Melo e Santos (2011) trazem como definição a relação entre o contexto econômico, político e social em que ocorre um desastre natural.

Outra possibilidade de caracterização dos desastres foi realizada por Alves et al. (2012) no artigo 4. Estes autores referem-se aos tipos de eventos que ocorrem, sendo caracterizados em naturais, tecnológicos, bélicos e sociais. Dentro dessa categorização, focalizando nos desastres ditos naturais, Freitas (2010), no artigo 8, cita as inundações, incêndios, terremotos, deslizamentos de terra, erupções vulcânicas, furacões, tornados, tsunamis, tempestades tropicais, secas, entre outros fenômenos.

Consequências dos Desastres: Questões Emocionais. Desastres provenientes de eventos da natureza geralmente têm impactos muito severos sobre as comunidades e pessoas afetadas. No que diz respeito às consequências, estas vão desde os danos imediatos ao evento como perdas humanas, materiais e desordem no cotidiano a desordens na vida pessoal e sofrimento psíquico e emocional.

Os autores destacam o grande número de afetados por desastres socioambientais no Brasil e convergem na perspectiva que este número é crescente. Nos artigos 1, 3, 5, 8, 9 e 10, os autores destacam, além das respostas imediatas no restabelecimento da ordem e socorro às vítimas, as consequências emocionais e os danos à saúde mental dos afetados.

Os autores dos artigos mencionados acima trazem à tona a discussão sobre os prejuízos emocionais em afetados, especialmente nos artigos 3 e 5, que se tratam de pesquisa teórico-empíricas realizadas diretamente em comunidades afetadas e que denunciam as angústias, sofrimentos e sensação de insegurança que permanecem mesmo com o passar do tempo.

Paranhos e Werlang (2015), no artigo 1, asseguram a importância e inclusão do apoio psicológico tanto para vítimas envolvidas diretamente na situação, assim como cada vez mais se tem dedicado especial atenção aos trabalhadores e voluntários que atuam nestes eventos. Dessa forma, mostra que a afetação por desastres acontece com todos os envolvidos no evento.

No artigo 10, de Krum e Bandeira (2008), os autores mencionam a ausência de estudos que investiguem acerca das consequências e dos processos psicológicos decorrentes de desastres, relatando um único estudo encontrado naquele momento. Fica explicitada a importância desse aspecto dado ao crescente número de publicações que enfatizam essa questão.

Manejo da Situação Traumática. Um desastre natural ou socioambiental demanda dos indivíduos afetados grande empenho em manejar a situação de catástrofe, e nos artigos analisados pode ser percebida a menção de enquadres teóricos que caracterizam as ações e reações empreendidas pela população afetada por desastres. Dentre as teorias em psicologia, são mencionados Coping, Identidade Coletiva e Resiliência. 
O coping é citado nos artigos 5, 9 e 10 como uma estratégia utilizada para o enfrentamento dos desastres e suas consequências. Coping pode ser definido, segundo Krum e Bandeira (2008) como sendo os esforços estáticos ou variantes utilizados pelo indivíduo, tanto a nível cognitivo quanto comportamental, para lidar com demandas internas e/ou externas específicas, que sobrecarregam ou excedem seus recursos pessoais.

Dentro das estratégias do coping, está inserida a busca por apoio social, que consiste em buscar auxílio de familiares, vizinhos, poder público ou mesmo a sociedade civil que se organiza em prol da colaboração com os indivíduos e comunidades afetadas.

No artigo 6, Lougon e Palassi (2012) apresentam o conceito da Identidade Coletiva que diz respeito a solidariedade entre os indivíduos em torno de um objetivo comum. Segundo esses autores, é por meio da identidade coletiva de uma comunidade que são "criadas expectativas que reforçam a manutenção da solidariedade grupal, pois os indivíduos identificam as consequências de sua quebra, como também, atribuem valor a ação das pessoas dentro e fora de seus grupos" (Lougon \& Palassi, 2012).

A Resiliência é mencionada no artigo 5 como uma forma de enfrentar os desastres. Mattedi (2008) a conceitua como sendo dispositivos subjetivos criados pelo sujeito para o enfrentamento de crises. Gomes e Cavalcante (2012) asseguram que através da Resiliência as pessoas conseguem manter um equilíbrio estável sem que tenham afetado o seu rendimento e a sua vida em geral quando acometidos por situações traumáticas.

Atuação/Contribuição da Psicologia. A atuação das psicólogas e psicólogos, e as contribuições que a Psicologia pode trazer em situações de desastre aparecem como o mote principal dos artigos levantados. Há uma preocupação em compreender as práticas até então realizadas, bem como buscar um melhor delineamento delas visando o fortalecimento de uma base teórica a fim de que se crie uma epistemologia que norteie a prática em Psicologia dos Desastres.

Essa categoria aparece nos artigos 1, 2, 3, 4, 5, 7, 9, 10 e 11 e versam sobre como a atuação da psicóloga e do psicólogo pode contribuir para a sociedade, comunidades afetadas e indivíduos. Os autores destacam que a atuação destes profissionais deve ocorrer em consonância com o que estabelece a Política Nacional de Defesa Civil (MIN, 2007), que estabelece como campos de atuação as medidas preventivas e de preparação, que envolvem o pré-desastre; medidas imediatas em resposta ao evento durante o seu acontecimento; e medidas de reconstrução e reparação que dão conta do pós-desastre.

A atuação no pré-desastre envolve os conceitos postulados por Mattedi (2008), no artigo 11, como a construção de comunidades mais seguras, o estabelecimento de redes de apoio para o enfrentamento e o conhecimento acerca do fenômeno. Melo e Santos (2011), no artigo 7, enfatizam que nesta fase, a psicóloga e o psicólogo podem contribuir nas medidas preventivas atuando junto às comunidades, nos núcleos comunitários que a Defesa Civil coordena.

Ainda no pré-evento, no artigo 3, Tavanti e Spink (2014) discorrem sobre o papel da psicóloga e do psicólogo na desconstrução das naturalizações sobre a convivência com os riscos, enfatizando o papel desses profissionais como possível agente interlocutor em um diálogo interdisciplinar e intersetorial necessário entre as diversas áreas de conhecimento científico, a Defesa Civil, os gestores públicos e a sociedade.

Durante o evento, Alves et al. (2012), no artigo 4, trazem as necessidades mais abrangentes da comunidade, que partem da atenção individual para o coletivo, com práticas de orientação de forma a proporcionar minimamente a estabilidade em uma situação caótica. Ações como planos de manejo hospitalar e socorro são possibilidades de atuação segundo os autores.

Alves et al. (2012), artigo 4, mencionam já no pós-desastres, que as ações empreendidas nesse momento, visam avaliar o sofrimento psíquico e atender as vítimas, bem como subsidiar futuras atuações mais eficazes. Para tanto, os autores sugerem o uso de escalas, entrevistas, questionários para verificação de incidência de transtorno de estresse Pós-traumático, ansiedade e sofrimento emocional.

No artigo 1, Paranhos e Werlang (2015) também mencionam ações com foco na resiliência emocional, no suporte social e no papel das equipes de resgate. Este outro aspecto na atuação da psicóloga e do psicólogo no pós-desastre, diz respeito à valorização das habilidades e condições que os afetados possuem de superar de forma positiva o estresse decorrente de uma situação catastrófica, tensionando outros modelos tradicionais da Psicologia, por vezes centrados apenas nas intervenções em patologias já estabelecidas (Paranhos \& Werlang, 2015).

Vale ressaltar que atuação da psicóloga e do psicólogo em um cenário de desastres, não ocorre isoladamente, mas sim em consonância com outras disciplinas 
afins, no intuito de se conseguir uma intervenção global e mais efetiva ao indivíduo ou comunidades afetadas. Esta observação vai ao encontro dos dados encontrados por Diniz Neto e Belo (2015) em estudo realizado, no qual os autores atentam para a exigência de práticas interdisciplinares no campo da Psicologia das Emergências e Desastres, assegurando que nas fases de desdobramento de um desastre, é fundamental o trabaIho de vários atores sociais.

\section{Considerações finais}

Este estudo teve como objetivo conhecer o modo como os desastres naturais ou socioambientais e os fenômenos intrínsecos a ele tem sido tomado como objeto de estudo pela psicologia, e mesmo com uma amostra relativamente pequena, foi possível perceber os desdobramentos das pesquisas nacionais sobre esse tema dentro a ótica da Psicologia.

A estratégia metodológica utilizada foi uma revisão sistemática da literatura nacional sobre Psicologia dos Desastres buscando duas das principais bases de dados nacionais de periódicos eletrônicos, a Bireme e a SciELO. Como a intenção era conhecer exclusivamente o que tem sido estudado no Brasil nos últimos 10 anos, a escolha por estas bases de dados mostrou-se pertinente e adequada.

Através deste estudo ficou explicitado os esforços das psicólogas, psicólogos e profissionais das áreas afins em compreender o fenômeno desastre e situá-lo dentro de realidade social e histórica do Brasil, uma vez que grande parte dos estudos buscam a definição de conceitos e a sua caracterização, certos de que as tramas que envolvem os desastres são muito complexas para sua redução em um termo.

Mesmo com todas as possibilidades de caracterização e conceituação dos desastres, os autores dos artigos levantados afirmam ser esta uma tarefa difícil dada as dimensões distintas a que eles provocam danos. Essa dificuldade em sua denominação, segundo Quarantelli (1998), poderia prejudicar os avanços no debate científico acerca do tema.

A ocorrência de uma maior produção na segunda metade da década de 2000 pode estar relacionada ao fato de que, a partir desse período houve um considerável aumento na incidência de desastres naturais no Brasil, tendo os anos de 2009, 2010 e 2012 os maiores registros de ocorrências. Observa-se ainda que foi no ano de 2011 que ocorreu o maior desastre natural do
Brasil até o momento, ocorrido na região serrana do Rio de Janeiro, resultando em 912 óbitos e mais de 45 mil pessoas desabrigadas ou desalojadas (MIN, 2012).

No mapa das produções ficou clara a predominância de estudos sobre desastres no Sul e Sudeste do país. Isso pode estar relacionado ao fato de que o Sul é a região onde mais ocorrem eventos extremos da natureza no país, e no Sudeste, apesar desses eventos ocorrerem em menor quantidade, devido à alta densidade demográfica tem um alto número de afetados (MIN, 2013).

A maioria dos estudos realizados foi de cunho teórico, em detrimento aos estudos teórico-empíricos. Essa realidade, de certa forma, mostra a fase embrionária que se encontra os estudos dentro da temática. Parece haver uma preocupação em conhecer profundamente o tema, que é complexo e envolve uma rede de conhecimentos e saberes que se intercruzam. É notória a interlocução de saberes quando se vê a busca por embasamento numa profunda discussão da conceituação e definição dos desastres, risco, prevenção e vulnerabilidade, ponto inicial para a ramificação de outras frentes de discussão.

Além de se conhecer o desastre como objeto isolado, há que se conhecer todo o contexto em que ele ocorre, assim, percebe-se um olhar atencioso para o indivíduo afetado. Esse olhar fica evidente quando é percebida a preocupação da atuação da psicóloga e do psicólogo no pré-desastre, colaborando na construção de comunidades mais seguras; durante o evento, minimizando as situações traumáticas e organizando os serviços e atenção, e no pós-evento, colaborando na reparação e reconstrução das comunidades, bem como oferecendo suportes para o acompanhamento da saúde mental dos afetados.

A psicologia nesse sentido, e seguindo a preconização do Conselho Federal de Psicologia [CFP] em nota técnica publicada em 2013, busca tirar esse indivíduo da condição de vítima, colocando-o como importante agente na contribuição da construção de um saber que o tornará protagonista nesse processo (CFP, 2013).

Através das pesquisas teórico-empíricas realizadas, é possível conhecer esse sujeito. Portanto, verifica-se a necessidade de continuamente dar voz a esses indivíduos, e isso se alcança, sobretudo, com um aumento de estudos de campo, que tragam visibilidade ao que realmente passam e sentem, que apontem onde as políticas públicas obtêm êxito ou falhas. Além disso, é importante a necessidade de estudos longitudinais, onde seria possível comparar dados e reparar

Estudos de Psicologia, 23(2), abril a junho de 2018, 179-188 
inconsistências nas estratégias de prevenção, enfrentamento e reconstrução das comunidades afetadas, mesmo isso representando um desafio no que se refere a recursos, que são menores para esse tipo de pesquisa em países em desenvolvimento, como afirmam Krum e Bandeira (2008). Todas essas propostas possibilitariam identificar como os desastres têm sido vivenciados pelas brasileiras e brasileiros.

Situando essas ações dos indivíduos dentro de uma perspectiva teórica da psicologia, o coping surge como a teoria mais mencionada nos trabalhos. Esta prática enumera as formas como o afetado enfrenta e reage ao desastre, tanto individualmente quanto coletivamente na construção de redes de apoio e suporte social. A resiliência também aparece como atributo amplamente discutido nos artigos.

Em resposta ao objetivo de conhecer o modo como os desastres socioambientais e os fenômenos intrínsecos a ele têm sido tomados como objeto de estudo pela psicologia, nota-se que este fenômeno ainda se mostra como um desafio para este campo de estudo. Porém, a perspectiva nos mostra que as bases teóricas para a Psicologia das Emergências e Desastres vêm sendo construída gradualmente, amparadas por um vasto escopo conceitual. Diniz Neto e Belo (2015) apontam para uma diversidade das linhas teóricas da Psicologia na qual são encontrados os estudos sobre emergências e desastres no Brasil, considerando este fato como um indicativo de que autores de diferentes abordagens estão se interessando e oferecendo contribuições.

Este fato poderá favorecer a construção de uma epistemologia própria, produzindo intervenções adequadas que contribuirão para a saúde e bem-estar do afetado encorajando-o no processo da construção de comunidades mais seguras.

\section{Referências}

Alves, R. B., Lacerda, M. A. C., \& Legal, E. J. (2012). A atuação do psicólogo diante dos desastres naturais: uma revisão. Psicologia em Estudo, 17(2), 307-315. doi: 10.1590/S1413-73722012000200014

Bardin, L. (2011). Análise de conteúdo.(L. A. Reto \& A. Pinheiro, Trads.). Portugal: Edições 70. (Obra original publicada em 1977)

Conselho Federal de Psicologia. (Org). (2013). Nota técnica sobre atuação de psicóloga (o)s em situações de emergências e desastres, relacionadas com a política de defesa civil. Brasília, DF: Autor. Recuperado de http://site.cfp.org.br/emergencias-e-desastres-2/

Diniz Neto, O., \& Belo, F. R. R. (2015). Psicologia das emergências. Gerais: Revista Interinstitucional de Psicologia, 8(n. spe), 284-299. Recuperado de http://pepsic.bvsalud.org/scielo.php?script=sci_arttext\&pid=S1983-82202015000200010\&lng=pt\&tlng=pt
Evangelista, J. D. (2009). Água benta e água consagrada: representações religiosas e representações de risco na periferia da cidade de São Carlos/SP. In N. Valencio et al. (Orgs.), Sociologia dos desastres: construção, interfaces e perspectivas no Brasil (pp. 131-145). São Carlos: Rima.

Favero, E., Sarriera, J. C., \& Trindade, M. C. (2014). O desastre na perspectiva sociológica e psicológica. Psicologia em Estudo, 19(2), 201-209. doi: 10.1590/1413-737221560003

Freitas, R. C. M. (2010). A construção de uma agenda para as questões de gênero, desastres socioambientais e desenvolvimento. Revista Estudos Feministas, 18(3), 889-899. doi: 10.1590/ S0104-026X2010000300014

Gomes, E. R. B., \& Cavalcante, A. C. S. (2012). Desastres naturais: perdas e reações psicológicas de vítimas de enchente em Teresina-PI. Psicologia \& Sociedade, 24(3), 720-728. doi: 10.1590/ S0102-71822012000300025

Krum, F. M. B., \& Bandeira, D. R. (2008). Enfrentamento de desastres naturais: o uso de um coping coletivo. Paidéia, 18(39), 73-84. doi: 10.1590/S0103-863X2008000100008

Lugon, A. P., \& Palassi, M. P. (2012). Participação dos núcleos de defesa civil do município de Vitória na gestão de desastres naturais. Revista Psicologia Política, 12(24), 345-361. Recuperado de http://pepsic.bvsalud.org/scielo.php?script=sci_arttext\&pi$\mathrm{d}=$ S1519-549X2012000200011\&lng=pt\&tIng=pt.

Mattedi, M. A. (2008). A abordagem psicológica da problemática dos desastres: um desafio cognitivo e profissional para a psicologia. Psicologia: Ciência e Profissão, 28(1), 162-173. doi: 10.1590/ S1414-98932008000100012

Melo, C. A., \& Santos, F. A. (2011). As contribuições da psicologia nas emergências e desastres. Psicólogo inFormação, 15(15), 169-181. doi: 10.15603/2176-0969/pi. v15n15p169-181

Ministério da Integração Nacional. (2007). Política Nacional de Defesa Civil. Brasília, DF: Secretaria Nacional de Defesa Civil. Recuperado de http://www.mi.gov.br/c/document_library/get_file?uuid=6aa2e891-98f6-48a6-8f47-147552c57f94\&groupld=10157

Ministério da Integração Nacional. (2012). Instrução Normativa oo 01, de 24 de agosto de 2012. Estabelece procedimentos e critérios para a decretação de situação de emergência ou estado de calamidade pública pelos Municípios, Estados e pelo Distrito Federal, e para o reconhecimento federal das situações de anormalidade decretadas pelos entes federativos e dá outras providências. Recuperado de http://www.mi.gov.br/c/document_library/get_file?uuid=822a4d42-970b-4e80-93f8-daee395a52d1\&groupld=301094

Ministério da Integração Nacional. (2014). Anuário brasileiro de desastres naturais. Brasília, DF: CENAD. Recuperado de http://www. mi.gov.br/c/document_library/get_file?uuid=fee4007a-ab0b-403e-bb1a-8aa00385630b\&groupld=10157

Paranhos, M. E., \& Werlang, B. S. G. (2015). Psicologia nas emergências: uma nova prática a ser discutida. Psicologia: Ciência e Profissão, 35(2), 557-571. doi: 10.1590/1982-370301202012

Quarantelli, E. L. (1998). Introduction: the basic question, its importance, and how is addresses in this volume. In E. L. Quarantelli (Org.), What is a disaster? Perspective on thequestion (pp. 01-7). Londres/Nova lorque: Routlege.

Silvestre, A. L. (2007). Análise de dados e estatística descritiva. Lisboa: Escolar Editora. 
Tavanti, R. M., \& Spink, M. J. (2014). Ações locais e prevenção: um estudo com adolescentes que vivem em áreas de risco socioambiental. Ambiente \& Sociedade, 17(4), 213-232. doi: 10.1590/1809-4422ASOC1120V1742014

Universidade Federal de Santa Catarina. Centro Universitário de Estudos e Pesquisas sobre Desastres. (2013). Atlas Brasileiro de Desastres Naturais 1991 a 2012: volume Brasil. Florianópolis: UFSC - CEPED. Recuperado de http://www.ceped.ufsc.br/ atlas-brasileiro-de-desastres-naturais-2012/
Valencio, N. (2009). Da morte de quimera à procura de Pégaso: a importância da interpretação sociológica na análise do fenômeno denominado desastre. In N. Valencio et al. (Orgs.), Sociologia dos desastres: construção, interfaces e perspectivas no Brasil (pp. 3-18). São Carlos: Rima.

Vargas, D. (2009). "Eu fui embora de lá, mas não fui”. In N. Valencio et al. (Orgs.), Sociologia dos desastres: construção, interfaces e perspectivas no Brasil (pp. 80-95). São Carlos: Rima.

\footnotetext{
1. A consulta às bases de dados foi realizada em 26 de abril de 2015.
}

Ana Paula de Araujo Braga, Mestre em Psicologia pelo Programa de Pós-Graduação em Psicologia da Universidade Federal do Espírito Santo (PPGP/UFES), é Psicóloga na Associação de Pais e Amigos dos Excepcionais de Vitória (APAE). Endereço para correspondência: Rua Aluysio Simões, 265 - Ap. 202, Bento Ferreira, Vitória, ES, CEP: 29050-637. Telefones: (27) 99791-2345 e (28) 99947-7415. E-mail: anapaula.abraga@hotmail.com

Priscilla de Oliveira Martins-Silva, Doutora em Psicologia pelo Programa de Pós-Graduação em Psicologia da Universidade Federal do Espírito Santo (PPGP/UFES), é Docente na Universidade Federal do Espirito Santo (UFES).

E-mail: priscillamartinssilva@gmail.com

Luziane Zacché Avellar, Doutora em Psicologia Clínica pela Pontifícia Universidade Católica de São Paulo (PUC/SP) e PósDoutora em Psicologia Clínica pelo Instituto de Psicologia USP, é Coordenadora do Programa de Pós-Graduação em Psicologia da Universidade Federal do Espírito Santo (PPGP/UFES). E-mail:luzianeavellar@yahoo.com.br

Kelly Guimarães Tristão, Doutora em Psicologia pelo Programa de Pós-Graduação em Psicologia da Universidade Federal do Espírito

Santo (PPGP/UFES), é Docente no Centro Universitário Faesa (FAESA). E-mail: kgtristao@hotmail.com

Pedro Machado Ribeiro Neto, Doutor em Psicologia pelo Programa de Pós-Graduação em Psicologia da Universidade Federal do Espírito Santo (PPGP/UFES) e Pós-Doutorado em Psicologia pelo Programa de Pós-Graduação em Psicologia da Universidade Federal do Espírito Santo (PPGP/UFES), é Docente no Centro Universitário do Espírito Santo (UNESC/Serra). E-mail: mrn.pedro@gmail.com

Recebido em 20.Mai.17 Revisado em 15.Mai.18 Aceito em 15.Ago.18 